Acta Crystallographica Section E

Structure Reports

Online

ISSN 1600-5368

\section{Sheng-Li Li, ${ }^{a}$ Jie-Ying $\mathrm{Wu}$, ${ }^{a}$} Yu-Peng Tian, ${ }^{a}$ Hoong-Kun Fun ${ }^{b_{*}}$ and Suchada Chantrapromma ${ }^{\mathrm{c}}$.

aDepartment of Chemistry, Anhui University, Hefei, Anhui 230039, People's Republic of China, ${ }^{\mathbf{b}} \mathrm{X}$-ray Crystallography Unit, School of Physics, Universiti Sains Malaysia, 11800 USM, Penang, Malaysia, and ${ }^{\mathrm{c}}$ Department of Chemistry, Faculty of Science, Prince of Songkla University, Hat-Yai, Songkhla 90112, Thailand

Correspondence e-mail: hkfun@usm.my,

suchada.c@psu.ac.th

\title{
Bis(thiosemicarbazide)zinc(II) bis(maleate) dihydrate.
} Erratum

In the paper by $\mathrm{Li}, \mathrm{Wu}$, Tian, Fun \& Chantrapromma [Acta Cryst. (2005), E61, m2701-m2703], there is an error with regard to the symmetry-code identifiers in the fourth paragraph of the Comment. The corrected sentence is 'The $\mathrm{N} 1-\mathrm{H} 1 \mathrm{~N} 1 \cdots \mathrm{O} 3, \mathrm{~N} 1-\mathrm{H} 2 \mathrm{~N} 1 \cdots \mathrm{S} 1^{\mathrm{ii}}$, N2-H1N2 . O $1^{\mathrm{iii}}, \mathrm{N} 3-$ $\mathrm{H} 1 \mathrm{~N} 3 \ldots \mathrm{O} 22^{\mathrm{iii}}$ and $\mathrm{N} 3-\mathrm{H} 2 \mathrm{~N} 3 \cdots \mathrm{O} 1^{\text {iv }}$ hydrogen bonds (see Table 2 for symmetry codes) link the complex cations and

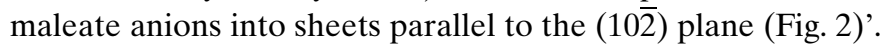

Received 6 December 2005 Accepted 8 December 2005 Online 16 December 2005 